\title{
Acute effects of calcium supplements on blood pressure and blood coagulation: secondary analysis of a randomised controlled trial in post-menopausal women
}

\author{
Sarah M. Bristow, Greg D. Gamble, Angela Stewart, Anne M. Horne and Ian R. Reid* \\ Department of Medicine, University of Auckland, Private Bag 92 019, Auckland 1142, New Zealand \\ (Submitted 1 April 2015 - Final revision received 13 August 2015 - Accepted 25 August 2015 - First published online 30 September 2015)
}

\begin{abstract}
Recent evidence suggests that Ca supplements increase the risk of cardiovascular events, but the mechanism(s) by which this occurs is uncertain. In a study primarily assessing the effects of various Ca supplements on blood Ca levels, we also investigated the effects of Ca supplements on blood pressure and their acute effects on blood coagulation. We randomised 100 post-menopausal women to $1 \mathrm{~g} / \mathrm{d}$ of $\mathrm{Ca}$ or a placebo containing no $\mathrm{Ca}$. Blood pressure was measured at baseline and every $2 \mathrm{~h}$ up to $8 \mathrm{~h}$ after their first dose and after 3 months of supplementation. Blood coagulation was measured by thromboelastography (TEG) in a subgroup of participants ( $n$ 40) up to 8 h only. Blood pressure declined over $8 \mathrm{~h}$ in both the groups, consistent with its normal diurnal rhythm. The reduction in systolic blood pressure was smaller in the Ca group compared with the control group by $>5 \mathrm{mmHg}$ between 2 and $6 \mathrm{~h}(P \leq 0.02)$, and the reduction in diastolic blood pressure was smaller at $2 \mathrm{~h}$ (between-groups difference $4.5 \mathrm{mmHg}, P=0.004$ ). Blood coagulability, assessed by TEG, increased from baseline over $8 \mathrm{~h}$ in the calcium citrate and control groups. At $4 \mathrm{~h}$, the increase in the coagulation index was greater in the calcium citrate group compared with the control group $(P=0.03)$, which appeared to be due to a greater reduction in the time to clot initiation. These data suggest that Ca supplements may acutely influence blood pressure and blood coagulation. Further investigation of this possibility is required.
\end{abstract}

Key words: Calcium supplements: Blood pressure: Blood coagulation: Randomised trials

Ca supplements, which have been widely recommended for the treatment and prevention of osteoporosis, have recently been associated with increased cardiovascular risk. In meta-analyses of randomised control trials by our group, Ca supplements, with or without vitamin $\mathrm{D}$, were associated with an increased risk of myocardial infarction and stroke ${ }^{(1,2)}$. These findings have been confirmed by others ${ }^{(3)}$. The mechanism by which Ca supplements increase cardiovascular risk is currently uncertain. As most of the studies suggest that dietary $\mathrm{Ca}$ is not associated with cardiovascular risk, we have hypothesised that the mechanism involves the increase in serum $\mathrm{Ca}$ that follows the ingestion of a supplement, as this is smaller or negligible after dietary $\mathrm{Ca}^{(4)}$. The elevation in serum $\mathrm{Ca}$ following a $500-1000 \mathrm{mg}$ dose of supplemental $\mathrm{Ca}$ is approximately $1 \mathrm{SD}$ of baseline values, is present for $>8 \mathrm{~h}$ and is not diminished with long-term use of $\mathrm{Ca}^{(5)}$. An elevation of this magnitude is likely to be clinically relevant, as a $1 \mathrm{SD}$ increase in serum $\mathrm{Ca}$ is associated with an increased risk of cardiovascular events in cohort studies $^{(6,7)}$

As $\mathrm{Ca}$ is involved in a diverse range of biological processes, there are a number of possible mechanisms by which $\mathrm{Ca}$ supplementation and the associated elevations in serum $\mathrm{Ca}$ could influence cardiovascular risk. Although an increase in vascular calcification has been suggested as the mechanism, the rapid increase in myocardial infarction risk after supplementation is initiated (within 1 year) ${ }^{(1,2)}$ suggests that a faster process is involved. Ca appears to acutely influence blood pressure, based on data following $\mathrm{Ca}$ infusions ${ }^{(8,9)}$, and thus this is a potential mechanism. Further, $\mathrm{Ca}$ is involved in blood coagulation, and platelets express the Ca-sensing receptor ${ }^{(10)}$, raising the possibility that changes in serum Ca could influence blood coagulability. However, very few studies have examined whether these indices of cardiovascular risk are affected acutely following the ingestion of a Ca supplement, at the time when serum Ca concentrations are elevated.

We recently carried out a randomised controlled trial in postmenopausal women, comparing the acute and 3-month effects of different $\mathrm{Ca}$ supplements on serum $\mathrm{Ca}$ and bone turnover. We found that serum $\mathrm{Ca}$ was elevated for at least $8 \mathrm{~h}$ following $1000 \mathrm{mg}$ of $\mathrm{Ca}$ supplementation ${ }^{(5)}$. As secondary, exploratory end points in this trial, we examined the acute and 3-month effects of Ca supplements on blood pressure and their acute effects on blood coagulation. As the commonly used laboratory measures of blood coagulation (prothrombin time and activated

Abbreviation: TEG, thromboelastography.

* Corresponding author: I. R. Reid, fax +649923 2375, email i.reid@auckland.ac.nz 
partial thromboplastin time) are measured in plasma collected into $\mathrm{Ca}$ chelator-containing tubes, they are unsuitable for examining the influence of physiological changes in serum $\mathrm{Ca}$ on whole-blood coagulation ${ }^{(11)}$. We, therefore, measured blood coagulation by thromboelastography (TEG), a point-of-care method that provides a global assessment of the coagulation system in native whole blood.

\section{Methods \\ Participants}

Participants were 100 women, who were at least 5 years postmenopausal. We excluded women if they had a history of CVD, if their 5-year cardiovascular risk was $>15 \%$ (assessed using tables published by the New Zealand Guidelines Group, www. nzgg.org.nz), if they had a major ongoing systemic illness, if they had taken any medication known to affect $\mathrm{Ca}$ or bone metabolism in the past year or if they were currently taking $>2000 \mathrm{IU} / \mathrm{d}(50 \mu \mathrm{g} / \mathrm{d})$ of vitamin $\mathrm{D}$. In the Ca group, nine women $(10 \%)$ received low-dose vitamin D supplements, as well as two $(12 \%)$ in the control group $(P=0.84)$. One participant reported regular usage of $>500 \mathrm{mg} / \mathrm{d}$ of supplemental Ca and was required to undergo a 6-month period of withdrawal before being enroled to the study. Thus, none of the participants were using Ca supplements at the time of the study. In the Ca group, nineteen women (25\%) received anti-hypertensive medication, as well as six (30\%) in the control group $(P=0.82)$. We recruited women from those who had volunteered to participate in a previous osteoporosis study by our group, but had been ineligible to do so because of normal bone mineral density (women had been recruited for that study via advertisement and mail-outs using electoral rolls). The flow of participants is presented in Fig. 1.

\section{Study design}

The study design has been described previously ${ }^{(5)}$. In brief, women were randomly assigned to the treatment group with $1 \mathrm{~g} / \mathrm{d}$ of $\mathrm{Ca}$ (twenty randomised to each of four groups receiving citrate, carbonate or two preparations of microcrystalline hydroxyapatite $(\mathrm{MCH})$, respectively) or to a placebo group with no $\mathrm{Ca}$ supplementation for 3 months. Randomisation was carried out by a computer-generated variable-block schedule prepared by staff who were not in contact with the participants. Calcium carbonate and calcium citrate (Jost Chemical Co.) were purchased from Hawkins Watts, and the $\mathrm{MCH}$ preparations were supplied by Waitaki Biosciences. All the interventions, including the placebo, were administered as identical encapsulated powders, from bottles labelled with the participant number by staff who were not in contact with participants. Participants and study staff were blinded to treatment allocation, although study staff were informed whether a participant was allocated to either the calcium citrate or the placebo group (but not which of these), as coagulation tests were only performed for these two groups. All four Ca treatment arms were pooled for the comparison of blood pressure effects with placebo. The comparison of coagulation factors was performed for the calcium citrate and placebo arms only (Fig. 1).

On day 1 of the study, participants attended our research clinic after fasting overnight. Blood pressure was measured, and subsequently a venous cannula was inserted and a blood samples were collected between 07.00 and 09.00 hours. The first dose of treatment (as $1 \mathrm{~g}$ of $\mathrm{Ca}$ or placebo) was administered with a glass of water. A light breakfast (peaches in juice and toast with margarine, jam, marmalade or honey) was provided following intervention. Blood pressure was measured, and subsequent blood samples collected at 2, 4, 6 and $8 \mathrm{~h}$ after the supplement was administered. A light lunch (fruit salad in juice and bread with margarine, jam, honey, marmalade or peanut butter) was provided after the $4 \mathrm{~h}$ sampling procedures were completed, and an optional snack (plain biscuits and decaffeinated tea) was provided after the $6 \mathrm{~h}$ sampling procedures were completed. Water and non-caffeinated tea without milk were allowed ad libitum.

After day 1, participants took their allocated supplements at home in two divided doses, with their morning and evening meals. We telephoned participants midway through the study to encourage compliance. After 3 months, participants returned to our clinic having taken their final dose of treatment the evening before, and a final fasting blood pressure measurement was taken. This study was conducted in accordance with the Declaration of Helsinki and was approved by the New Zealand Northern Regional X Ethics Committee. Written informed consent was obtained from all the participants. This study is registered with the Australia New Zealand Clinical Trials registry (ACTRN12611000232932).

\section{Measurements}

Blood pressure was measured using a Dinamap automatic monitor (Johnson \& Johnson). After a 5 min period of rest in a sitting position, three recordings were taken at 3 min intervals, as programmed automatically by the device. Across the cohort, the first recording at each time point was found to be significantly higher than the following two recordings; therefore, the mean of the second and third recordings was used in the analyses.

Blood coagulation was measured by TEG on participants allocated to the calcium citrate or placebo group. The calcium citrate group was selected for these measurements because they are time-consuming to perform and because this group was expected to have substantial increases in serum $\mathrm{Ca}$ levels $^{(12)}$. TEG is based on the motion of a pin suspended in a rotating cup containing a blood sample. As blood begins to clot, the increased viscosity of the blood causes the pin to move along with the cup. This motion allows calculation of various indices of blood coagulation, including the time to clot initiation (denoted the R-time), rate of clot formation ( $\alpha$-angle and $\mathrm{K}$-time) and the strength of the final clot (maximum amplitude $)^{(13)}$. From these four values, the coagulation index can be calculated, and describes a patient's overall coagulation status - more positive values indicating increased coagulation and more negative values indicating reduced coagulation. Blood coagulation was measured using a TEG 


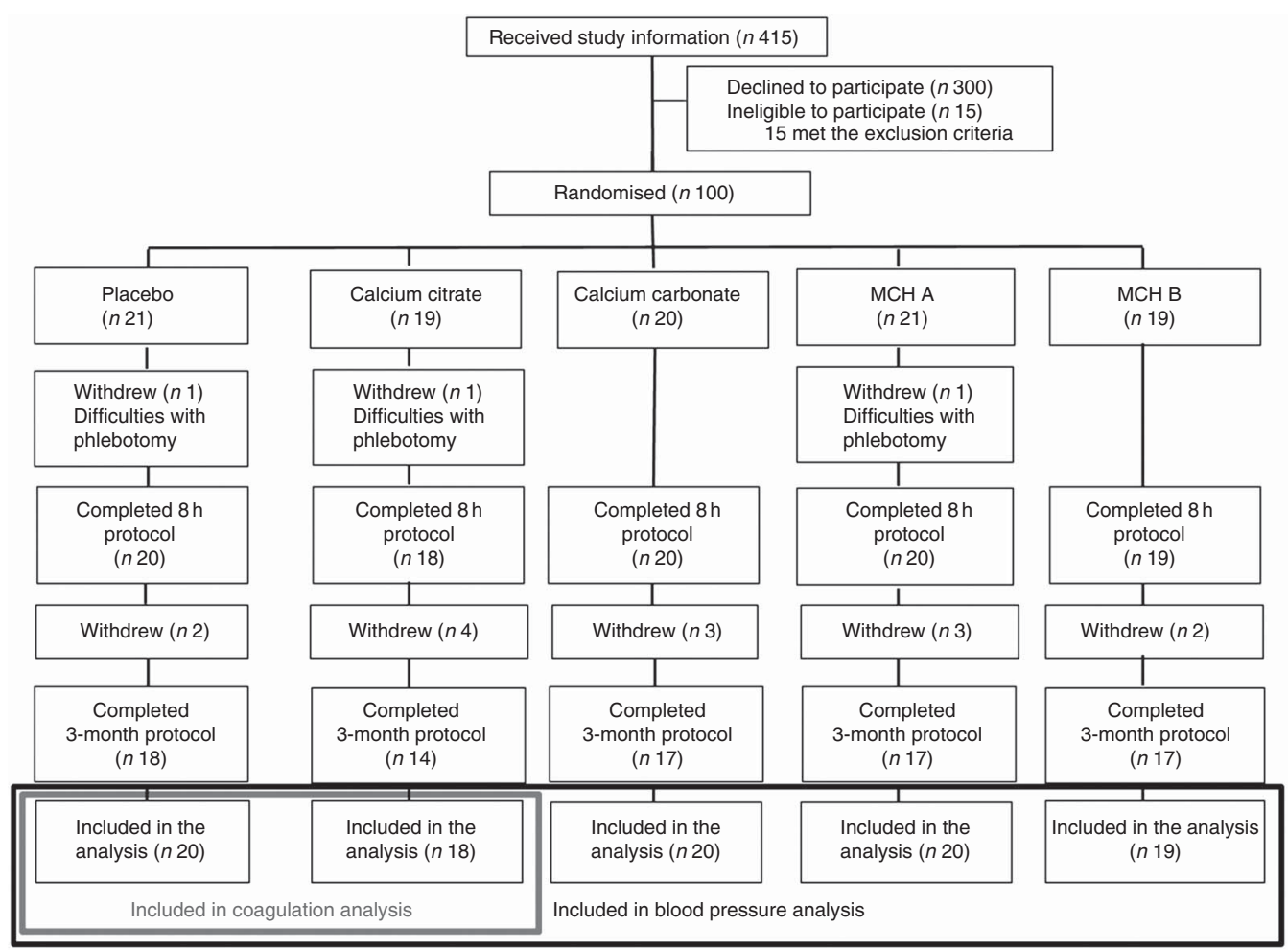

Fig. 1. Flow of participants through the study. Only participants allocated to the calcium citrate or placebo groups had blood coagulation measured. One participant in the control group and two participants in the calcium citrate group did not have blood coagulation measured due to technical problems with the device. These participants did not contribute to the coagulation data of the study and were not included in the analysis of blood coagulation data. One participant in the Ca group declined to have blood pressure measured. This participant did not contribute to the blood pressure data of the study and was not included in the analysis of blood pressure data. $\mathrm{MCH}$, microcrystalline hydroxyapatite.

5000 Thromboelastograph Hemostasis Analyzer as per the manufacturer's guidelines. At each time point, $2-3 \mathrm{ml}$ of blood was drawn from the venous cannula into a syringe and discarded. A further 1-2 $\mathrm{ml}$ of blood was then drawn into a syringe and gently transferred to a test tube. From this, $360 \mu \mathrm{l}$ of blood was immediately transferred into a pre-warmed cup loaded into the TEG device. The TEG tracing was initiated $4 \mathrm{~min}$ after blood was drawn from the cannula.

\section{Statistical analyses}

A mixed effects model repeated measures ANCOVA with change from baseline to each time point for each end point as the dependent variable and with the baseline value of the end point variable as the covariate (unstructured covariance) was used to construct an appropriate error term for each of the comparisons between treatment and control at each time point. The assumption of normality was verified for each dependent variable. The main effects of treatment allocation and time and a time by treatment allocation interaction effect were fitted. Contrasts were pre-specified to limit the number of pair-wise comparisons that were performed to those between treatment arms at each time point (i.e. four comparisons at each time point for each variable), and a false discovery rate-adjusted $P$ value was calculated to preserve an overall $5 \%$ significance level for each end point. Day 1 and day 90 data were analysed independently. Mean values with their standard errors changes from baseline are plotted (without covariate/mixed model adjustment). Analyses were performed using SAS (version 9.4; SAS Institute Inc.). Comparison between variables at baseline was made using Student's $t$ tests, as all the variables listed satisfied the requirements for normality and homogeneity of variances. All the tests were two-tailed, and $P<0.05$ was considered to be significant.

\section{Results}

The baseline clinical and biochemical characteristics of the participants are presented in Table 1 . Changes in serum $\mathrm{Ca}$, phosphate and parathyroid hormone levels in this study have been reported elsewhere ${ }^{(5)}$.

\section{Blood pressure}

Changes in blood pressure are presented in Fig. 2. Systolic blood pressure and diastolic blood pressure were significantly lower than baseline at all time points between 2 and $8 \mathrm{~h}$ in both the control and the Ca groups (all time points $P<0 \cdot 001$ ). There was a consistent pattern in the change in blood pressure over $8 \mathrm{~h}$ in both the groups. Both systolic and diastolic pressures showed dips at 2 and $6 \mathrm{~h}$, the two postprandial time points. When we examined changes from baseline at individual time points, the reductions in systolic blood pressure from baseline were smaller in the $\mathrm{Ca}$ 
Table 1. Baseline characteristics of participants (Mean values, standard deviations and ranges)

\begin{tabular}{|c|c|c|c|c|c|c|c|}
\hline & \multicolumn{3}{|c|}{ Ca supplement } & \multicolumn{3}{|c|}{ Control } & \multirow[b]{2}{*}{$P$} \\
\hline & Mean & SD & Range & Mean & SD & Range & \\
\hline & \multicolumn{3}{|c|}{$(n 77)$} & \multicolumn{3}{|c|}{$(n 20)$} & \\
\hline Age (years) & 69 & 5 & 59,84 & 68 & 3 & 63,74 & 0.23 \\
\hline Weight (kg) & 74.4 & $13 \cdot 3$ & 50,114 & 71.6 & $9 \cdot 2$ & 55,88 & 0.38 \\
\hline Height $(\mathrm{m})$ & 1.62 & 0.06 & $1.47,1.78$ & 1.63 & 0.06 & $1.50,1.70$ & 0.41 \\
\hline BMI $\left(\mathrm{kg} / \mathrm{m}^{2}\right)$ & $28 \cdot 4$ & $4 \cdot 8$ & $19 \cdot 2,46 \cdot 5$ & $27 \cdot 0$ & 4.6 & $18.5,33.9$ & 0.25 \\
\hline Dietary Ca (mg/d) & 860 & 380 & 240,2140 & 900 & 500 & 340,2220 & 0.72 \\
\hline 25-Hydroxyvitamin D (nmol/l) & 72 & 21 & 29,132 & 68 & 18 & 31,112 & 0.46 \\
\hline Systolic blood pressure (mmHg) & 132 & 19 & 94,209 & 126 & 20 & 99,167 & 0.2 \\
\hline Diastolic blood pressure (mmHg) & 72 & 8 & 52,90 & 72 & 8 & 55,84 & 0.86 \\
\hline TEG variables & & $(n 18)$ & & & $(n 20)$ & & \\
\hline Coagulation index ${ }^{*}$ & -1.5 & 1.4 & $-4 \cdot 2,1 \cdot 3$ & $-1 \cdot 8$ & 1.4 & $-4 \cdot 7,0.3$ & 0.52 \\
\hline R-time $(\min ) \dagger$ & $17 \cdot 6$ & $5 \cdot 3$ & $7.9,28.9$ & $17 \cdot 1$ & 3.9 & $11 \cdot 3,24 \cdot 8$ & 0.78 \\
\hline K-time (min) $\ddagger$ & $9 \cdot 0$ & $2 \cdot 7$ & $4 \cdot 5,13 \cdot 7$ & $9 \cdot 3$ & $3 \cdot 2$ & $4 \cdot 6,15 \cdot 8$ & 0.76 \\
\hline a-Angle $\left({ }^{\circ}\right) \ddagger$ & $24 \cdot 6$ & $6 \cdot 4$ & $16 \cdot 8,37 \cdot 6$ & 24.5 & $7 \cdot 2$ & $14 \cdot 4,42 \cdot 5$ & 0.97 \\
\hline Maximum amplitude $(\mathrm{mm}) \S$ & $50 \cdot 0$ & $5 \cdot 7$ & $38,58.3$ & 47.4 & $6 \cdot 1$ & $33.5,54.9$ & 0.21 \\
\hline
\end{tabular}

TEG, thromboelastography.

* Overall assessment of coagulability calculated from R-time, K-time, $a$-angle and maximum amplitude.

$\dagger$ Time to clot initiation.

₹ Rate of clot formation.

$\S$ Strength of the final clot.

(a)

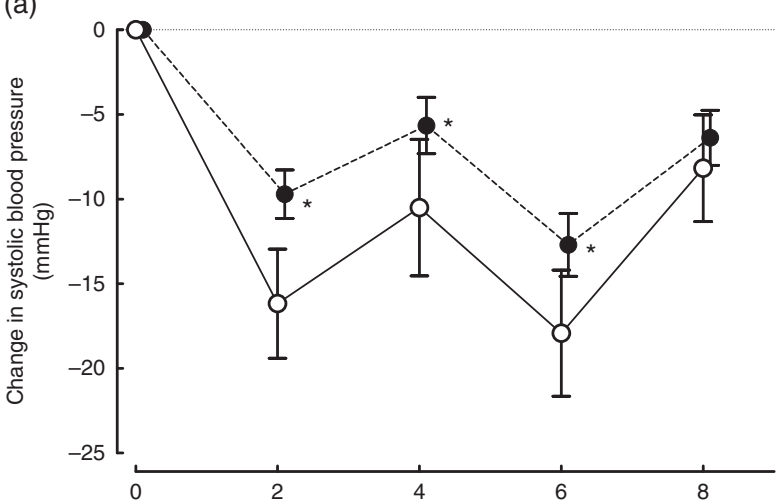

(b)

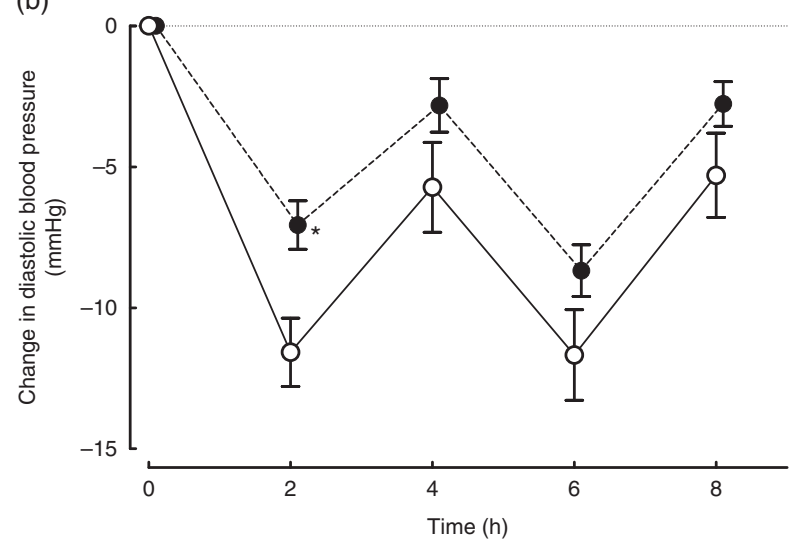

Fig. 2. Changes (a) systolic and (b) diastolic blood pressures in postmenopausal women over $8 \mathrm{~h}$ after the ingestion of $1000 \mathrm{mg}$ of $\mathrm{Ca}(-, n 76)$ or a placebo containing no $\mathrm{Ca}(-\mathrm{O}, \mathrm{n20})$. Values are means with their standard errors. Changes from baseline in systolic blood pressure were significantly different between the $\mathrm{Ca}$ and placebo groups between 2 and $6 \mathrm{~h}($ all $P<0.02$ ) and diastolic blood pressure at $2 \mathrm{~h}(P=0.004)$. ${ }^{*}$ Significantly different from the control group $(P<0.02)$. group compared with the placebo at $2(P=0.003), 4(P=0.02)$ and $6 \mathrm{~h}(P=0.01)$. Similarly, the reductions in diastolic blood pressure were smaller in the Ca $v$. placebo group at $2 \mathrm{~h}(P=0.004)$ and close to significant at $4(P=0.07)$ and $6 \mathrm{~h} \quad(P=0.06)$. Restricting the analyses to those not using anti-hypertensive medication produced the same pattern of results. After 3 months of supplementation, systolic and diastolic blood pressures were not different from baseline in the $\mathrm{Ca}$ or placebo groups (all $P>0.31)$ and were not different between the groups at this time point (all $P>0 \cdot 80$ ). Comparable effects on blood pressure were seen across the four different types of Ca supplement groups.

\section{Blood coagulation}

Blood coagulability tended to increase over $8 \mathrm{~h}$ in both the groups, reflected by an increase in the coagulation index at all time points between 2 and $8 \mathrm{~h}$ in the $\mathrm{Ca}$ (all time points $P<0.007$ ) and control (all $P<0.042$ ) groups (Fig. 3). The increase from baseline in the coagulation index was significantly greater in the Ca group compared with the control group at $4 \mathrm{~h}(P=0.03)$. This appeared to be primarily due to a reduction in the time to clot initiation, as this was significantly shorter in the Ca group compared with the control group at $4 \mathrm{~h}$ $(P=0.03)$. The other TEG variables from which the coagulation index is calculated (reflecting the rate of clot formation and strength of the final clot) were not different between the Ca and control groups at any time point (data not shown).

\section{Discussion}

\section{Blood pressure}

Blood pressure declined from baseline over $8 \mathrm{~h}$ in both the $\mathrm{Ca}$ and control groups. This reduction is likely due to the normal 
(a)

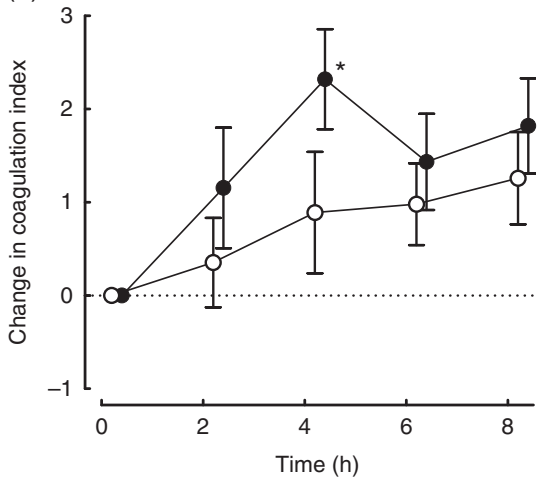

(b)

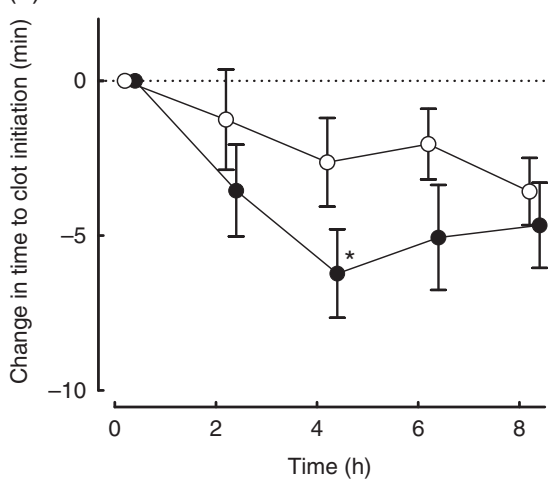

Fig. 3. Changes in the thromboelastographic measures of blood coagulation (a) coagulation index and (b) time to clot initiation (R-time) in post-menopausal women over $8 \mathrm{~h}$ after the ingestion of $1000 \mathrm{mg}$ of $\mathrm{Ca}$ as citrate $(-, n 16)$ or a placebo containing no $\mathrm{Ca}(-\mathrm{O}, n 19)$. Changes from baseline in the coagulation index and time to clot initiation were significantly different between the calcium citrate and placebo groups at $4 \mathrm{~h}$ (both $P=0.03$ ). ${ }^{*}$ Significantly different from the control group, $P=0.03$. Values are means with their standard errors.

diurnal variation in blood pressure, which is characterised by a surge in the morning ${ }^{(14)}$. The consistent pattern we observed in blood pressure dip at 2 and $6 \mathrm{~h}$, the time points following the two meals, suggests that feeding also influenced blood pressure in our study. In healthy older adults, the ingestion of a meal has been shown to result in a $11 \mathrm{mmHg}$ reduction in systolic blood pressure, similar to the magnitude of the reduction in the control group of the present study ${ }^{(15)}$.

The reduction in blood pressure over $8 \mathrm{~h}$ tended to be smaller in the Ca group compared with the control group, with the difference between groups being significant at some time points (between 2 and $6 \mathrm{~h}$ for systolic blood pressure and at $2 \mathrm{~h}$ for diastolic blood pressure). These differences were $5 \mathrm{mmHg}$ or more, large enough to be biologically significant. To our knowledge, our study is the first randomised placebo-controlled trial to examine the acute effects of $\mathrm{Ca}$ supplements on blood pressure. Two recent, small, uncontrolled studies examined the changes in blood pressure at one time point following $\mathrm{Ca}$ supplementation $^{(16,17)}$. In both the studies, serum Ca increased 2 or $3 \mathrm{~h}$ after the Ca supplementation, but blood pressure did not change from baseline. However, in the absence of a control group, those studies were unable to address the effect of $\mathrm{Ca}$ supplementation on blood pressure, independent of the endogenous diurnal rhythm. Both previous studies were performed after fasting ${ }^{(16,17)}$, which may also have contributed to the differences between their findings and ours.

The long-term (weeks to months) effects of Ca supplementation on blood pressure have been examined in a number of clinical trials, and the relationship between dietary Ca intake and blood pressure has been assessed in epidemiological studies. In meta-analyses of these studies, Ca supplementation and higher dietary $\mathrm{Ca}$ intakes have been associated with modest but significant reductions in blood pressure ${ }^{(18-20)}$. In contrast, a separate body of evidence supports a direct relationship between serum $\mathrm{Ca}$ and blood pressure. In epidemiological studies, increased serum $\mathrm{Ca}$ concentrations have been associated with higher blood pressure ${ }^{(7,21)}$ and pulse pressure $^{(22,23)}$. In a small trial, ionised $\mathrm{Ca}$ increased by $0.32 \mathrm{mmol} / \mathrm{l}$ after $\mathrm{Ca}$ infusion and systolic blood pressure increased by $7 \mathrm{mmHg}^{(8)}$. In a similar study, ionised $\mathrm{Ca}$ increased step-wise by 0.10 and $0.20 \mathrm{mmol} / \mathrm{l}$ after $\mathrm{Ca}$ infusion and systolic blood pressure increased by 5 and $10 \mathrm{mmHg}^{(9)}$. Furthermore, in patients on dialysis, increases in serum $\mathrm{Ca}$ and smaller reductions in blood pressure during dialysis have been observed with the use of high-Ca dialysates ${ }^{(24)}$.

The differing relationships of serum $\mathrm{Ca}$ and $\mathrm{Ca}$ intake with blood pressure can be explained by the fact that high dietary $\mathrm{Ca}$ intakes and $\mathrm{Ca}$ supplementation do not result in sustained higher serum Ca concentrations, due to the tight regulation of extracellular Ca levels to a physiological set-point ${ }^{(25)}$. However, it is well-known that extracellular $\mathrm{Ca}$ concentrations can be increased to the upper levels of their normal range or above in the period immediately following the ingestion of a $\mathrm{Ca}$ supplement ${ }^{(5,26)}$. Therefore, it is possible that Ca supplements might have different effects on blood pressure acutely, when serum Ca concentrations are elevated, compared with $>8-12 \mathrm{~h}$ later when serum $\mathrm{Ca}$ concentrations have returned to their baseline levels. The finding of the present study of a difference in blood pressure between the $\mathrm{Ca}$ and placebo groups only within $8 \mathrm{~h}$ following supplementation, but not after 3 months of supplementation (when blood pressure was measured in the morning after an overnight fast), is consistent with this hypothesis.

If Ca supplements do result in an acute elevation in blood pressure, or less of a reduction in blood pressure from fasting or morning values, then there are several possible mechanisms through which this might be mediated. In rats, the administration of a calcimimetic produces an acute rise in blood pressure $^{(27,28)}$, suggesting the Ca-sensing receptor, which is expressed throughout the vasculature ${ }^{(29)}$, may be involved. Changes in extracellular $\mathrm{Ca}$ and/or Ca-regulatory hormones could influence blood pressure through alterations in the renin-angiotensin-aldosterone system $^{(30)}$. A change in extracellular Ca levels could influence intracellular Ca levels, and thus increase the tone of vascular smooth muscles. The postprandial reduction in blood pressure that occurs in older adults might be attenuated by an increased release of vasoactive gut hormones such as glucagon-like peptide $1^{(31)}$, which may in 
turn be influenced by the Ca content of the meal ${ }^{(32)}$. Correspondingly, the ingestion of a Ca supplement with breakfast attenuated the usual postprandial fall in vascular tone in one small trial ${ }^{(33)}$.

\section{Blood coagulation}

Blood coagulability increased in both the $\mathrm{Ca}$ and placebo groups over $8 \mathrm{~h}$, which may have been due to diurnal variations in activators and inhibitors of coagulation. Alternatively, phlebotomy and sample collection may have influenced our TEG results ${ }^{(34)}$ - for example, any increase in difficulty in drawing blood from the cannula over $8 \mathrm{~h}$ may have resulted in activation of clotting factors and platelets.

There was a greater reduction in the time to clot initiation and correspondingly a greater increase in the coagulation index at $4 \mathrm{~h}$ in the $\mathrm{Ca}$ group compared with the control. To our knowledge, this is the first study to examine the acute effects of Ca supplements on blood coagulation. In a study in rats, hypercalcaemia significantly shortened the time to clot initiation $^{(35)}$. In a study of citrated and re-calcified human blood samples, ionised Ca was inversely associated with the time to clot initiation and was positively associated with the strength of the clot $^{(11)}$. Across the physiological range of $\mathrm{Ca}$ values, the time to clot initiation was linearly and inversely related to ionised $\mathrm{Ca}$ concentration. If Ca supplements and/or changes in extracellular $\mathrm{Ca}$ did influence clotting, then this might be mediated through increased activation of the clotting cascade, in which $\mathrm{Ca}$ is an essential cofactor. Platelets, which have an essential role in the initiation of coagulation, also express the Ca-sensing receptor ${ }^{(10)}$, suggesting extracellular $\mathrm{Ca}$ concentrations could influence their activity. It has recently been demonstrated that platelet activation is greater in patients with primary hyperparathyroidism than it is following surgical cure of that condition ${ }^{(36)}$, suggesting that elevated serum $\mathrm{Ca}$ might directly activate these cells.

Strengths of the present study include its randomised controlled design and measurement of blood pressure and blood coagulation at multiple time points. Limitations of this study include the relatively small size of the control group ( $n$ 20), which was due to the primary outcome (change in markers of bone turnover) being a comparison between five groups ${ }^{(5)}$. The differences we identified in blood pressure and blood coagulation only reached significance at some time points. Nonetheless, the effects demonstrated are novel, and are large enough to be pathophysiologically significant, and also provide a basis for further research examining the acute effects of $\mathrm{Ca}$ supplements on indices of cardiovascular risk. As this study was conducted in a group of older women, the changes in blood pressure and coagulation may not apply to other age groups or to men.

In conclusion, this study has identified two putative mechanisms by which $\mathrm{Ca}$ supplements might impact on cardiovascular risk - through acute increases in both blood pressure and in blood coagulation immediately following dosing. The potential importance of these findings and the fact that the changes are only significant at some time points both suggest that confirmation by independent studies is required.
However, these preliminary observations could be important in helping us understand the adverse effects of Ca supplements on vascular health.

\section{Acknowledgements}

This work was supported by the Health Research Council of New Zealand. Some of the analyses in this study were funded by a Sir Charles Hercus Health Research Fellowship awarded to Mark J. Bolland. S. M. B. is the recipient of a University of Auckland Doctoral Scholarship. The funders had no role in the design, analysis or writing of this article.

The author contributions to the manuscript are as follows: S. M. B. and I. R. R. designed the study; S. M. B., A. S. and A. H. conducted the study; G. D. G. analysed the data; S. M. B., I. R. R. and G. D. G. wrote the manuscript; and S. M. B. and I. R. R. had primary responsibility for the final content. All the authors critically reviewed and approved the final version of the manuscript.

There are no conflicts of interest to declare.

\section{References}

1. Bolland MJ, Avenell A, Baron JA, et al. (2010) Effect of calcium supplements on risk of myocardial infarction and cardiovascular events: meta-analysis. BMJ 341, c3691.

2. Bolland MJ, Grey A, Avenell A, et al. (2011) Calcium supplements with or without vitamin D and risk of cardiovascular events: reanalysis of the Women's Health Initiative limited access dataset and meta-analysis. BMJ 342, d2040.

3. Mao PJ, Zhang C, Tang L, et al. (2013) Effect of calcium or vitamin D supplementation on vascular outcomes: a metaanalysis of randomized controlled trials. Int J Cardiol 169, 106-111.

4. Karkkainen MU, Wiersma JW \& Lamberg-Allardt CJ (1997) Postprandial parathyroid hormone response to four calciumrich foodstuffs. Am J Clin Nutr 65, 1726-1730.

5. Bristow SM, Gamble GD, Stewart A, et al. (2014) Acute and 3-month effects of microcrystalline hydroxyapatite, calcium citrate and calcium carbonate on serum calcium and markers of bone turnover: a randomised controlled trial in postmenopausal women. Br J Nutr 112, 1611-1620.

6. Slinin Y, Blackwell T, Ishani A, et al. (2011) Serum calcium, phosphorus and cardiovascular events in postmenopausal women. Int J Cardiol 149, 335-340.

7. Jorde R, Sundsfjord J, Fitzgerald P, et al. (1999) Serum calcium and cardiovascular risk factors and diseases: the Tromso study. Hypertension 34, 484-490.

8. Nilsson IL, Rastad J, Johansson K, et al. (2001) Endothelial vasodilatory function and blood pressure response to local and systemic hypercalcemia. Surgery 130, 986-990.

9. Kamycheva E, Jorde R, Haug E, et al. (2005) Effects of acute hypercalcaemia on blood pressure in subjects with and without parathyroid hormone secretion. Acta Physiol Scand 184, 113-119.

10. House MG, Kohlmeier L, Chattopadhyay N, et al. (1997) Expression of an extracellular calcium-sensing receptor in human and mouse bone marrow cells. J Bone Miner Res $\mathbf{1 2}$, $1959-1970$

11. James MF \& Roche AM (2004) Dose-response relationship between plasma ionized calcium concentration and thrombelastography. J Cardiothorac Vasc Anesth 18, 581-586. 
12. Thomas SD, Need AG, Tucker G, et al. (2008) Suppression of parathyroid hormone and bone resorption by calcium carbonate and calcium citrate in postmenopausal women. Calcif Tissue Int $\mathbf{8 3}, 81-84$.

13. Karon BS (2014) Why is everyone so excited about thromboelastrography (TEG)? Clin Chim Acta 436, 143-148.

14. Pickering TG, Shimbo D \& Haas D (2006) Ambulatory blood-pressure monitoring. N Engl J Med 354, 2368-2374.

15. Lipsitz LA \& Fullerton KJ (1986) Postprandial blood pressure reduction in healthy elderly. J Am Geriatr Soc 34, 267-270.

16. Burt MG, Mangelsdorf BL, Srivastava D, et al. (2013) Acute effect of calcium citrate on serum calcium and cardiovascular function. J Bone Miner Res 28, 412-418.

17. Yaron M, Roach V, Izkhakov E, et al. (2014) Effects of a typical acute oral calcium load on arterial properties and endothelial function in healthy subjects. Eur J Clin Nutr 68, 608-612.

18. Van Mierlo LA, Arends LR, Streppel MT, et al. (2006) Blood pressure response to calcium supplementation: a metaanalysis of randomized controlled trials. I Hum Hypertens 20, 571-580.

19. Griffith LE, Guyatt GH, Cook RJ, et al. (1999) The influence of dietary and nondietary calcium supplementation on blood pressure: an updated metaanalysis of randomized controlled trials. Am J Hypertens 12, 84-92.

20. Dickinson HO, Nicolson DJ, Cook JV, et al. (2006) Calcium supplementation for the management of primary hypertension in adults. Cochrane Database Syst Rev, issue no. 2, CD004639.

21. Sabanayagam C \& Shankar A (2011) Serum calcium levels and hypertension among U.S. adults. J Clin Hypertens (Greenwich) 13, 716-721.

22. Mateus-Hamdan L, Beauchet O, Rolland Y, et al. (2014) Association of calcium concentration with pulse pressure in older women: data from a large population-based multicentric study. J Nutr Health Aging 18, 323-329.

23. Hagström E, Ahlström T, Ärnlöv J, et al. (2015) Parathyroid hormone and calcium are independently associated with subclinical vascular disease in a community-based cohort. Atherosclerosis 238, 420-426.

24. Locatelli F, Cavalli A \& Tucci B (2010) The growing problem of intradialytic hypertension. Nat Rev Nephrol 6, 41-48.
25. Houillier P, Froissart M, Maruani G, et al. (2006) What serum calcium can tell us and what it can't. Nephrol Dial Transplant 21, 29-32.

26. Heaney RP, Dowell MS, Bierman J, et al. (2001) Absorbability and cost effectiveness in calcium supplementation. J Am Coll Nutr 20, 239-246.

27. Fryer RM, Segreti JA, Widomski DL, et al. (2007) Systemic activation of the calcium sensing receptor produces acute effects on vascular tone and circulatory function in uremic and normal rats: focus on central versus peripheral control of vascular tone and blood pressure by cinacalcet. J Pharmacol Exp Ther 323, 217-226.

28. Odenwald T, Nakagawa K, Hadtstein C, et al. (2006) Acute blood pressure effects and chronic hypotensive action of calcimimetics in uremic rats. J Am Soc Nephrol 17, 655-662.

29. Smajilovic S \& Tfelt-Hansen J (2007) Calcium acts as a first messenger through the calcium-sensing receptor in the cardiovascular system. Cardiovasc Res 75, 457-467.

30. Vaidya A, Brown JM \& Williams JS (2015) The reninangiotensin-aldosterone system and calcium-regulatory hormones. J Hum Hypertens 29, 515-521.

31. Gentilcore D, Bryant B, Wishart JM, et al. (2005) Acarbose attenuates the hypotensive response to sucrose and slows gastric emptying in the elderly. Am J Med 118, 1289.

32. Gonzalez JT \& Stevenson EJ (2014) Calcium co-ingestion augments postprandial glucose-dependent insulinotropic peptide(1-42), glucagon-like peptide-1 and insulin concentrations in humans. Eur J Nutr 53, 375-385.

33. Soares MJ, Kuriyan R \& Kurpad AV (2010) Calcium and vitamin D modulate postprandial vascular function: a pilot dose-reponse study. Diab Met Syn: Clin Res Rev 4, 128-131.

34. Chitlur M \& Lusher J (2010) Standardization of thromboelastography: values and challenges. Semin Thromb Hemost 36, 707-711.

35. Hilgard P (1973) Experimental hypercalcaemia and whole blood clotting. J Clin Pathol 26, 616-619.

36. Yilmaz H (2014) Assessment of mean platelet volume (MPV) in primary hyperparathyroidism: effects of successful parathyroidectomy on MPV levels. Endocr Regul 48, 182-188. 